\title{
Teaching and Learning of Grammar at the Basic Level of Education: Revisiting Inductive Teaching Approach
}

\author{
Gifty Edna Anani \\ Department of Public Relations, Faculty of Communication and ICT, University of Professional Studies, Accra, Ghana
}

\section{Email address:}

gifty.anani@upsamail.edu.gh

\section{To cite this article:}

Gifty Edna Anani. Teaching and Learning of Grammar at the Basic Level of Education: Revisiting Inductive Teaching Approach. Education Journal. Vol. 6, No. 1, 2017, pp. 51-62. doi: 10.11648/j.edu.20170601.17

Received: August 19, 2016; Accepted: January 4, 2017; Published: February 22, 2017

\begin{abstract}
Literature on approaches to teaching grammar favours the inductive approach as a better strategy for building students' grammatical and communicative skills than the deductive approach. This present study investigated whether pupils who were taught grammar through the inductive approach would do better than those taught through the deductive approach. The design chosen for the study is the quasi experimental placed in a mixed method paradigm. Data were collected from a sample of 99 participants (comprising 27 Junior High School English Language teachers and 72 pupils). Data were collected using class tests and observation. Data was analyzed by the use of Statistical Package for Social Sciences (SPSS). Findings indicate that those who were taken through inductive teaching showed better skills than those who were taken through the deductive method. Finally, it is recommended that teachers of English Language adopt the inductive teaching approach to teach grammar because it helps students to grasp grammar rules easily.
\end{abstract}

Keywords: Grammar, Inductive Teaching, Deductive Teaching, Action Research, Acquisition

\section{Introduction}

In Ghana, English language serves many roles. For instance, it is the medium of instruction in schools, the official language of government administration and the major language of the internet. Besides, it is also the language across the curriculum, that is, the language used to teach all subjects with the exception of Ghanaian languages. To this extent, educational success in Ghana depends largely on proficiency in English. One cannot proceed to the next level of education without a credit pass in the English language. From earlier studies on the English language [1] [2] [17] there appears to be a decline in standards of English Language among student users and many researchers are attributing this perceived problem to many factors including methodology used by teachers, students' own attitudes and environmental factors. [2] attests to the fact that the English Language appears to be indispensable to Ghanaians and teachers of English Language and examiners have persistently raised concerns about the falling standard of English Language.

[1] shares the same view. He states that 'The standard of English in Ghana is deteriorating and there is the need for teachers to help arrest the situation'. Apart from many researchers' views on the decline, many questions are being asked in respect of this decline of standards in the country. From the preliminary studies on the topic being discussed, the present researcher observed that some students from the Junior High School fail their Basic Education Certificate Examination (B. E. C. E) because they cannot express themselves competently in writing. The 2012 Chief examiners' report [31] attests to this problem. This is a national issue requiring attention as English language serves as an effective communication tool in a multilingual country like Ghana. Any deficiency in the language will impede the flow of communication [6] [5] confirms this view when he indicated that

The way a communication system works is known as its grammar and both sender and the recipient need to use grammar if they are to understand each other. If there is no grammar, there can be no communication.

The above statement underscores the importance of grammar teaching in the basic schools. This means that for good communication to take place, the message should get to its destination effectively without any barrier. In order to achieve effective communication, therefore, the message sent 
should be devoid of grammatical errors such that comprehension is hindered.

[9] views grammar knowledge is very important; it enables students to communicate accurately, meaningfully, and appropriately. From this assertion, one could see another importance of grammar, which is, helping students with the structure they need to carry their messages across. [19] shares the same view:

Grammar is the backbone of a language and without it any single thing you do may be flux. Grammar provides you with structure in order to organize your messages and ideas across. It is the railway through which your messages will be transported. In the same way, since a train cannot move without railway, one cannot convey his or her message effectively without the right structure of the language.

There is clear evidence that grammar cannot be ruled out in our schools, hence the need to teach it well to enable students grasp all the grammatical skills. Although the role of teachers in the grammar classroom is very crucial, some teachers at the basic level take grammar teaching for granted. Many see grammar teaching as the easiest subject to teach and teach it with the mind that students will understand easily. Besides, there should be best practices in teaching grammar to help students understand and apply the rules effectively in their day to day communication. As a tutor of the English language of a college of education, I had the chance to supervise teachers and teacher-trainees' lessons in their various classrooms and saw that most grammar structures were not handled with the needed expertise. It is expected that teachers would be able to adopt appropriate and effective strategies to teach grammar in the language classroom. However, it appears many teachers are not trained to explore other methods apart from the traditional grammar memorization method. The researcher believes it is proper for educators to consider suitable methods for teaching grammar because strategies teachers adopt to teach their students really counts. [17] attests to this notion:

Rotten teaching methods also play significant part in affecting the learner of English adversely. A teacher may sometimes dole out awful lessons without realizing just how lousy it is.

\section{Deductive and Inductive Teaching Approaches}

Deductive teaching is a traditional approach in which information about the target language and rules are driven at the beginning of the class and continued with examples. The principles of this approach are generally used in the classes where the main target is to teach grammar structures. For instance, deductive principles are convenient for situations where grammar translation method is applied [15]. According to [25] three basic principles, a deductive lesson starts with presentation of the rules by the teacher. Secondly, the teacher gives examples by highlighting the grammar structures. Then students practise with the rules and produce their own examples at the end of the lesson [25] On the other hand, inductive teaching, according to [15] involves a process where learners discover the grammar rules themselves by examining given examples. In an inductive approach, it is also possible to use a context for grammar rules. Here, learners explore the grammar rules in a text or an audio rather than isolated sentences. [25]notes that in an inductive approach, learners are provided with samples which include the target grammar that they will learn. Then learners work on the examples and try to discover the rules themselves.

A deductive approach is based on the top-down theory in which the presentation and explanation of grammar rules take precedence over teaching. The language is taught from the whole to parts so learners understand the grammar rules and structures first. Next, they see the examples provided by their teacher and finally they begin to produce their own examples.

In contrast to this, an inductive approach is based on the bottom-up theory which accepts the view that language learners tend to focus on parts rather than the whole. For this reason the teaching process begins with a text, audio or visual in a context. Secondly learners work on the material to find the rules themselves. In the final stage, they give their own examples [25]. The deductive approach is more teachercentred while the inductive approach is more student-centred.

The merit of the inductive-deductive debate lies in which approach in reality yields or seems to yield better results at a given level. Presently it seems preference for the deductive approach is motivated more by convenience than results as the inductive approach appears to be more cumbersome and time consuming. With the present outcry over declining standards of English usage among Ghanaian learners, it is imperative to highlight how the inductive approach to the teaching of grammar can turn around things. Consequently, this study seeks to explore the effectiveness of the inductive method in teaching grammar at the basic school level and also find appropriate activities to help students grasp the correct structure.

\subsection{Objectives of the Study}

The objectives of the study are:

i. To examine the strategies teachers use in teaching grammar in the language classroom

ii. To assess the impact of inductive teaching and the challenges teachers face when using this strategy.

iii. To develop inductive teaching activities to help teachers to teach grammar effectively.

\subsection{Research Questions}

i. What are the strategies teachers use to teach grammar in the language classroom at the Junior high school(JHS) level?

ii. Do students taught inductively perform better than those taught deductively?

iii. What are some of the inductive teaching activities that can help students of the JHS understand and apply grammar rules effectively? 


\section{Theoretical Framework}

This section focuses on various theories that have been used to support the current study.

\subsection{Action Research}

The term Action Research first appeared in the works of Kurt Lewin in 1934, who is rightly seen as the 'father' of Action Research. [21] defines action research as a process, "which gives credence to the development of powers of reflective thought, discussion, decision and action by ordinary people participating in collective research on 'private troubles' they have in common". "If you want it done right, you may as well do it yourself", is the aphorism that seems to direct the tenets of Action Research. Action research is "learning by doing." - A group of people identify a problem, do something to resolve it, see how successful their efforts are, and if not satisfied, try again or review the strategy.

Several attributes separate action research from other types of research. The Primary one is its focus on turning the people involved into researchers. People learn best, and are more willing to apply what they have learned when they do it themselves. Its social dimension is that the research takes place in real-world situations, and aims to solve real problems. Finally, the initiating researcher, unlike in other disciplines, makes no attempt to remain objective, but openly acknowledges his or her bias to the other participants.

[22] gives a somewhat more elaborate listing. He distinguishes five phases involved within each research cycle. Initially, a problem is identified and data is collected for a more detailed diagnosis. This is followed by a collective postulation of several possible solutions, from which a single plan of action emerges and is implemented. Data on the results of the intervention are collected and analyzed, and the findings are interpreted in the light of how successful the action has been. At this point, the problem is re-assessed and the process begins another cycle. This process continues until the problem is resolved.

[26] outlines some principles of action research which include reflexive critique (where people reflect on issues and processes and make explicit their interpretations) biases, assumptions and concerns upon which judgments are made, dialectical critique, collaborative resource, risk, plural structure and theory, practice, and reformation.

The major tenet of Action Research is captured in a study done by [12]. According to [12]. There are four steps involved in the process of conducting Action Research and this includes the following:

a) Identifying an area of focus,

b) Collecting data,

c) Analyzing and interpreting the data,

d) Developing an action plan.

[27] also included more steps in the action research process to provide a clear-cut picture of the research development for the individual conducting the investigation. Their steps included the following: a) Identifying the area of focus,

b) Writing the action plan to guide the inquiry process,

c) Collecting data to address the identified question,

d) Organizing the data,

e) Analyzing and interpreting the data,

f) Sharing the findings.

This theory is relevant to the current study because this methodology will be employed by the researcher. To adequately investigate the right methodology of teaching that will produce desired results in grammar, it is essential that the researcher be part of the study to bring out the clear picture of the issue to be studied. Hence, the researcher will take active part in identifying the area of focus, collect data, analyze and interpret the data and develop an action plan to rectify the problem.

\subsection{Theories of Language Acquisition}

There are several theories that have been propounded on how language is acquired by humans. These are explicated below.

Reinforcement theory: This theory asserts that children learn to speak like adults because they are praised and rewarded for their appropriate use of the language. This theory stems from well-known Learning by Operant Conditioning theories stemming from the works of B. F. Skinner. Although the Reinforcement theory is inadequate to explain how children get the rules of the grammar of the language since children are impervious to corrections and the corrections of parents are mostly not accurate, the theory also provides good explanations for how children get to repeat correct grammar expressions as and when they are rewarded on its appropriate usage. [23]

Active Construction of a Grammar theory: This holds the view that children form the rules of grammar themselves. It holds that the ability to develop the rules is innate but the actual rules are derived from what they hear from others; this is their input for data analysis. Children listen to speeches around them and analyze them based on what already exists. When they are able to match what they hear to the rules that are innate, they use them in subsequent utterances.

Connectionist theories: This theory assumes that language learners learn new languages by forming neural connections in the brain. A child develops these connections by using a language or being exposed to a language. Through these connections, the child learns the meanings of words, associations between words, sound sequences and so on. All these theories are important to this research since they explain how language is acquired by language learners. The focus of this research is to see whether inductive or deductive or an eclectic approach is the right way to help language learners acquire the rules of the English language. The theories above will facilitate the understanding of what basis children have in acquiring languages.

Social Interaction Theory: The social interaction theory is also another theory that explains that children acquire the rudiments of a language as a result of their interaction with parents, peers and significant other. The approach holds that 
children prompt their parents to supply them with the appropriate language experience they need. Although like Active Constructionists they also believe that children have the predispositions for a language, they emphasize more on the social interactions that children have and how this affects their language. They consider the children and the language environment as a dynamic system; children need their language environment to improve their social and communication skills.

\section{Method}

\subsection{Mixed Method}

Generally, there are different types of mixed methods and six of them have been listed below:

a) The convergent parallel design

b) The explanatory sequential design (Quantitativequalitative)

c) The explanatory sequential design (Qualitative Quantitative)

d) The embedded design

e) The transformative design

f) The multiphase design

From the above stated types of mixed method designs, the researcher adopted design B, explanatory sequential design, because quantitative data was collected and analyzed first, followed by the qualitative data. For the quantitative data, the researcher gave out close ended questions to JHS 2 English teachers in La - Nkwantanang municipality to respond to. Also, Pre and post-tests were administered to some of the students at Nkwantanang cluster of schools. For the qualitative, the researcher used four weeks to observe all the JHS schools at the Nkwantanang cluster of schools. This was done to confirm the approaches teachers use in class and also observe students response to grammar teaching.

\subsection{Research Design}

Making the current research as efficient as possible, the researcher employed quasi-experimental design which gave a better picture of the problem identified.

Quasi - Experimental Design.

There are many forms of quasi-experiments but the one chosen for the current work is Pre-post-test with experimental and control groups. The experimental group is exposed to the intervention/ treatment exercise. On the other hand, the control group is left without any treatment. Figure 1 explains further pre - test-post - test with control group.

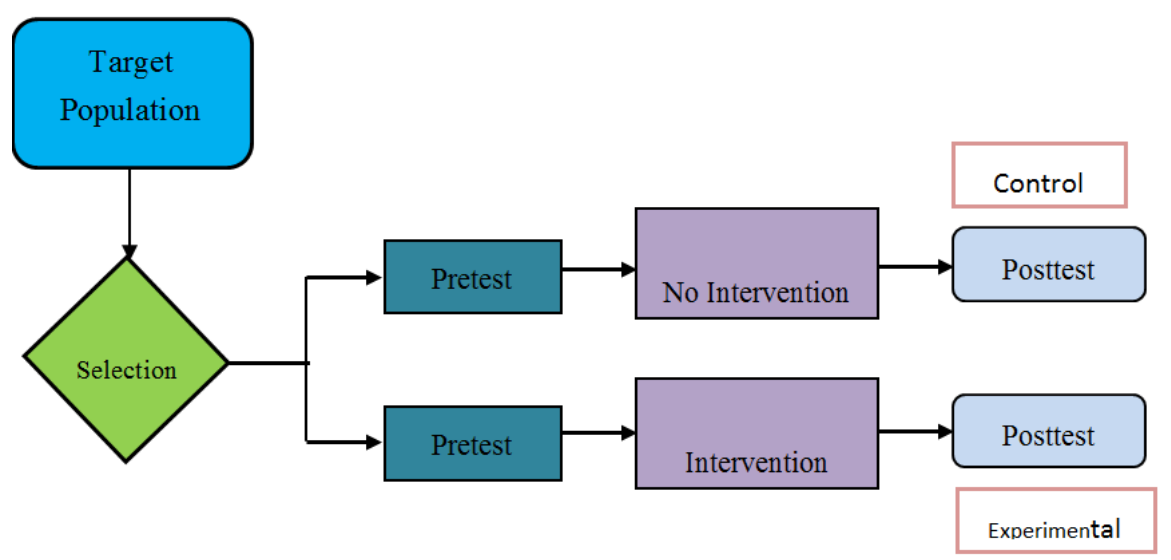

Figure 1. Quasi-experiment.

Adapted: nationaltechcenter. org [33]

From the description given on the design, the researcher adopted the Pretest-posttest with control and experimental groups. The reason for the selection was that it helped the researcher to do a better comparative study of the control and experimental group. For an effective research, the researcher went through the following processes to collect data for analysis. (A detailed description is given under data collection procedure.)

i. 1 Pre-intervention (pre - test)

[4] explains that pre-test can find out the level of the students' knowledge and ability before the intervention starts, and so performs a useful diagnostic function. He further states that tests during an intervention can gauge progress, increase motivation, and act as a further diagnostic measure. In order to identify the actual problem at hand, the researcher adopted this procedure to diagnose the perceived research problem before the actual intervention or treatment. What the researcher did was to select a composition topic, with the title, "What I do on Sundays", in their English textbook. The reason for a composition exercise was that the researcher did not want to test students' knowledge of grammar in isolation. She wanted to know how students use their grammar knowledge to express themselves orally and in writing. To get the clear picture, the two groups: control and experimental groups, were all put in their various classrooms for two periods, that is, 70 minutes to write the composition. This exercise really helped the researcher to identify some of the grammatical errors they make in their written compositions. From all the mistakes identified, the researcher chose Subject-verb agreement (Concord) because it was the most pervasive error. Again, the researcher acknowledges that a firm grasp of the knowledge of concord will help solve the major error problems students and even adult users of 
English language face in their day to day activities. An intervention/treatment stage was then devised to treat the problem identified.

\section{ii. Intervention process (Treatment stage)}

This process is about series of measures put in place to treat the problem identified. The current researcher used about three months to implement an approach to teach grammar effectively at the JHS 2 level. The major problem identified in their compositions, as stated earlier was subjectverb agreement. The researcher then prepared a detailed lesson plan based on subject-verb agreement to teach the experimental group to help overcome the subject-verb agreement errors. With the inductive approach, the learner first studies examples in which the grammatical structure is used, without having met the rule, and from these examples he or she has to develop an understanding of the rule [28]. Inductive language learning is quite similar to the way native speakers acquire their language and thus the approach is often associated with the Direct Method and the Natural Approach [28]. The deductive approach, on the other hand, proposes the introduction of the rules, memorizing and applying them. The researcher used deductive approach to teach the control group. After these rigorous exercises, the researcher gave the same composition lesson to the two groups to test the impact or effectiveness of the inductive teaching and learning.

\section{iii. Post-Intervention}

This stage evaluated the outcome of the approach chosen. This was to ascertain whether the experimental group who were introduced to the inductive approach performed better than those introduced to deductive teaching. The researcher administered a second test, named post- test for this exercise.

\subsection{Population}

The current study was carried out in La - Nkwantanang Municipality. La - Nkwantanang is located in the Greater Accra Region. According to the 2010 population census, the population is 161,873 out of which 51 percent is male and 49 percent female. It is therefore a male dominated area. In terms of education, the municipal assembly has universities, secondary schools, vocational schools, junior secondary schools and primary schools. There are about 1,426 [34] teachers in the public and private schools in the area. Also, the number of JHS schools in the municipality is 94 of which 37 are public schools and 57 private schools.

\subsection{Sample}

With regard to the current study, the researcher selected 17 schools for the collection of the data. Out of the 17 schools, 4 schools at Nkwantanang cluster of schools were selected for observation and intervention lessons. Redco M/A 2 A and B schools were chosen as the experimental and the control groups. Questionnaires were also administered to all teachers from the 17 schools selected. The main reason for selecting these schools is the convenience of having all schools around Madina which were close to the researcher's station. Another reason for selecting Nkwantanang was because the majority of the students stayed around the schools so the students' attendance was generally good. This really helped the researcher because students were all the time present for the intervention lessons.

\subsection{Sampling}

For the current study, the researcher used purposive sampling to select all the schools of study. Purposive sampling is the process whereby the researcher selects a sample based on experience or knowledge of the group to be sampled. Also, [30] advise that subjects to be surveyed should be selected purposively if possible, from the population of interest as they possess the information the researcher wants to obtain. Even though, purposive sampling has disadvantages, the researcher chose it because she needed to be sure that she could work with the participants to test the impact of the teaching method being studied. The researcher purposively selected 17 schools out of the 94 . The researcher did this because of accessibility of the school. To add to this, the researcher used the same purposive technique to sample the schools for the observation study and the intervention processes. All 4 JHS Form 2 schools at Nkwantanang cluster of schools were selected for the observation. Out of the 4 schools, one school was selected for the intervention lessons. The school had 2 classes, A and B. 36 students were chosen from Group A to represent the experimental group and 36 from group B as the control group. There was no sampling because all those who were available were used.

\subsection{Data Collection Instrument}

Data allows us to look over the researcher's shoulder and see what he saw. Data makes research empirical, and empirical research is highly valued because it represents something outside our opinions and ourselves [11] Examples of data collection instruments include questionnaires, various types of tests, observation schemes, and transcription protocols. The instruments used for collecting data for this study were observation, pre-test, and post-test.

\section{STUDY 1}

\subsection{Data Collection Procedure}

This section gives a detailed description of what was (or will be) done in carrying out a study.

For smooth flow of the exercise, the researcher used observation and pre- test, intervention or treatment and posttest.

There was the need to go to the selected schools to have first - hand information on what English teachers do in the grammar classroom. The researcher sought permission from the respective headteachers of the schools selected for the observation exercise. Each headteacher called for a short meeting with the English Language teachers for a briefing on the study. Later, the researcher was introduced to the students for a similar exercise. This was to win the confidence of the participants and eliminate any possible aversion towards the 
study. The researcher used four weeks for the class observation, appearing twice every week. After the observation exercise, the researcher devoted four weeks for the intervention processes.

\section{a Pre-Intervention}

The researcher gave a composition exercise on "What I do on Sundays" which is found in their JHS 2 English textbook (page 80). The reason for choosing this exercise was that the researcher wanted to know how grammatical structure is used. Also, she did not want to test their grammar skills in isolated sentences. The students did not take the exercise home to write. They sat in class for 70 minutes to write the essay. I had the exercise very smooth because all the English teachers in the school gave me a helping hand. After 70 minutes, the two groups, experimental and the control group handed all their compositions to the researcher. To add to this, the researcher used one week to mark the exercises and the results really confirmed that indeed there was a problem. Below is a classification of the errors students made.

Common errors from the students' composition

- Verb tense errors

- Subject-verb agreement errors

- Noun-pronoun errors

- Double negatives errors

- Sentence fragment errors

- Spellings errors

- Homonyms errors

- Preposition errors

- Conjunction errors

Sample Errors from students' composition

Subject-verb agreement errors

"I goes to church every day"............ I go to church everyday

"My brother and 1 plays football"............ My brother and I play football

I and my brother goes to church............ My brother and I go to church

My friend and I enjoys churches. My friend and I enjoy church

"The work I do are"... The work I do is

The church close at $12 \mathrm{pm}$ The church closes at $12 \mathrm{pm}$

Nobody wear............ Nobody wears
Spelling errors
Weather........... whether
Iam............ am
whiles............ While/whilst
Trueout........... Throughout
then............. Than
Super............ supper
brakefast........... breakfast.
Hoseholdchoirs............ household chores
Foodstaff............ foodstuff
Mob............ Mop
Joy nows............ joy news
Brash........... brush
Possessive errors

fathers' car............. Father's car.
Girls's school............ Girls' school.
Gladys's dress............ Gladys' dress
Preposition errors
Prefer than............ Prefer to

I go to church about $9.00 \ldots \ldots . . . . .$. I go to church at 9.00

My mother tells us stories on the evening ...... in the evening.

From the above problems identified, the researcher used one week to prepare for the intervention. The actual intervention section took four weeks. Two weeks for control and another two weeks for the experimental group. The researcher used inductive teaching to teach the experimental group and deductive for the control group.

From the above problems identified, the researcher used one week to prepare for the intervention. The actual intervention section took four weeks. Two weeks for control and another two weeks for the experimental group. The researcher used inductive teaching to teach the experimental group and deductive for the control group.

$b$ Intervention Experimental group lesson on subject verb agreement/ concord

The researcher prepared a detailed lesson plan based on subject-verb agreement (appendix I) to teach this class. Her aim for teaching this class was for the students to use target structure effectively in their essays. This is the aim of every language teacher. [3] attests to this fact that lessons in the syllabus and textbook aim at getting students use the grammatical structure accurately and fluently to express themselves. To go by the aim stated above, the researcher took students through 3 stages. The following are the stages for the lesson.

Presentation: The lesson on subject-verb agreement was demonstrated in meaningful situations. Researcher/ teacher used role play, dialogue, dramatization, conversation and videos to introduce the structure. Later, sentences were formed to help the students grasp the grammar structure then students were asked to form sentences using the target structure because the topic was not new, students were able to predict what they would be doing. The students were involved in lots of activities. To help them use subject-verb agreement appropriately so researcher adopted [18] activities for inductive teaching:

Activities for inductive instruction:

1. The presentation context may come from something in the classroom,

2. Visuals such as a photo, an illustration in the textbook.

3. From the teacher's or students' own lives.

4. Authentic texts (listening to recorded texts or listening to dialogues to highlight grammatical structures; student then come out with rules

5. Recorded conversations: Watch videos and narrate by using structure to report what they listened to. [18]

After these rigorous exercises, students were asked to deduce rules from the sentences given.

a Discussion and explanation: The students were involved in a lot of activities. My purpose at this 
stage was to help them use subject-verb agreement appropriately. Sentences were given for students to look up for verbs and subjects agreement.

Looking up for the subject and the verb: Students decide on whether subjects were singular or plural, then match with the appropriate verb.

Examples

\section{I sweep}

You sweep

Mary she sweeps

We sweep

Peter and James sweep

Sentences used for the lesson

The girls walk to school

$\mathrm{S}(\mathrm{p}) \quad \mathrm{V}(\mathrm{s})$

The girl walks to school

$\mathrm{S}(\mathrm{s}) \quad \mathrm{V}(\mathrm{s})$

The woman is asleep

$\mathrm{S}(\mathrm{s}) \quad \mathrm{V}(\mathrm{s})$

The women are asleep

$\mathrm{S}(\mathrm{p}) \quad \mathrm{V}(\mathrm{p})$

The English teacher always comes to school

$\mathrm{S}(\mathrm{s}) \quad \mathrm{V}(\mathrm{s})$

The English teachers always come to school

$\mathrm{S}(\mathrm{p}) \quad \mathrm{V}(\mathrm{p})$

My friends go to church on Sundays

$\mathrm{S}(\mathrm{p}) \quad \mathrm{V}(\mathrm{p})$

My friend goes to church on Sundays

$\mathrm{S}(\mathrm{s}) \quad \mathrm{V}(\mathrm{s})$

Nobody is perfect

$\mathrm{S}(\mathrm{s}) \quad \mathrm{V}(\mathrm{s})$

Each of us has a role to play in class

$\mathrm{S}(\mathrm{s}) \quad \mathrm{V}(\mathrm{s})$

Not one of them is here

$\mathrm{S}(\mathrm{s}) \quad \mathrm{V}(\mathrm{s})$

Either of them is likely to finish the work

$\mathrm{S}(\mathrm{s}) \quad \mathrm{V}(\mathrm{s})$

None of the players is good.

$\mathrm{S}(\mathrm{s}) \quad \mathrm{V}(\mathrm{s})$

One of my brothers has traveled

$\mathrm{S}(\mathrm{s}) \quad \mathrm{V}(\mathrm{s})$

Each of my sisters is educated

$\mathrm{S}(\mathrm{s}) \quad \mathrm{V}(\mathrm{s})$

Every one of the students has registered for BECE

$\mathrm{S}(\mathrm{s}) \quad \mathrm{V}(\mathrm{s})$

Either the English teachers or the mathematics teacher was here.

$\mathrm{S}(\mathrm{p}) \quad \mathrm{S}(\mathrm{s}) \quad \mathrm{V}(\mathrm{s})$

Either my father or my aunties come here.

$\mathrm{S}(\mathrm{s}) \quad \mathrm{S}(\mathrm{s}) \quad \mathrm{V}(\mathrm{p})$

The news is broadcast on all the radio stations.

$\mathrm{S}(\mathrm{s}) \quad \mathrm{V}(\mathrm{s})$

Mathematics is a good subject

$\mathrm{S}(\mathrm{s}) \quad \mathrm{V}(\mathrm{s})$

The United Nations is trying for world peace
$\mathrm{S}(\mathrm{s}) \quad \mathrm{V}(\mathrm{s})$

A hundred dollars is a huge amount of money

$\mathrm{S}(\mathrm{s}) \quad \mathrm{V}(\mathrm{s})$

Gladys is a good woman

$\mathrm{S}(\mathrm{s}) \quad \mathrm{V}(\mathrm{s})$

Somebody was working for my father

$\mathrm{S}(\mathrm{s}) \quad \mathrm{V}(\mathrm{s})$

My family goes out every Sunday for dinner

$\mathrm{S}(\mathrm{s}) \quad \mathrm{V}(\mathrm{s})$

My family are great scientists

$\mathrm{S}(\mathrm{p}) \quad \mathrm{V}(\mathrm{p})$

The class has decided to go on an excursion

$\mathrm{S}(\mathrm{s}) \quad \mathrm{V}(\mathrm{s})$

The football team is playing on the field.

$\mathrm{S}(\mathrm{s}) \quad \mathrm{V}(\mathrm{s})$

The audience was small

$\mathrm{S}(\mathrm{s}) \quad \mathrm{V}(\mathrm{s})$

Control Group

The control group, on the other hand, received tuition through the deductive teaching approach. They were also taken through 3 stages. The only difference in the tuition was that students were introduced to the rules before the explanation and discussion.. Later, students were asked to study the rules and form sentences with it.

Evaluation and exercise: [3] states that the purpose of this stage is to provide students with extra practice that allows one to see the extent to which the lesson objectives had been achieved. The researcher gave students extra time to work in groups by narrating their personal experiences. Later, the various groups gave their reports to the class.

\section{$b$ Post intervention:}

This was the final stage to test the students' performance on the targeted structure so the same composition exercise was given to control and experimental groups. It was a sit - in test and they were given 70 minutes to write. The results of the test is analyzed in the next section.

\subsection{Methods Used for Data Analysis}

Due to the quantitative and qualitative data collected, the researcher adopted descriptive statistics to analyze the quantitative data.. On the other hand, narrative analysis was also adopted to analyze data from the observational study.

\subsubsection{Summary of Major Findings}

As stated earlier in section one, the main aim of the study was to test the effectiveness of the inductive teaching of grammar. The study focused on the approaches teachers used to teach grammar and students attitude to grammar lessons. The summary of the main findings were put under two broad areas namely, observation and class experiment conducted.

STUDY 2

\subsubsection{Observation}

A frequent source of information in case study research is observation of the research setting by the researcher. Unlike interviews, which rely on people's sometimes biased perceptions and recollections of events, observations of a 
setting by a case study researcher may provide more objective information related to the research topic. However, conducting a meaningful observation requires skill and persistence [7] [20] proposed 5 principles to guide researchers in conducting observational research. Below are the five principles:

1. Identifying what must be observed in order to shed light on possible answers to the research questions.

2. Creating an observation guide, a list of features to be addressed during a particular observation (This list often includes the time/date/location of the observation names/positions of persons being observed, specific activities and events related to the research questions, and initial impressions and interpretations of the activities and events under observation.)

3. Anticipating that participants in the setting may be suspicious of the researcher's goals; the researcher must be prepared to explain why, how, and for whom the investigation is being carried.

4. Recognizing his or her personal role and biases related to the research. Unlike other forms of research in which the researcher attempts to maintain distance from the setting and activities, case study researchers are usually immersed in their work.

5. Minimizing risks; to balance any risks with potential benefits of the research and to inform participants of any risks involved. For the current study, the researcher considered the above mentioned principles. The first thing the researcher did was to prepare a checklist to guide her in getting the information she was looking for. Below were items she observed:

1. The methods teachers use in the grammar classroom

2. Teaching and learning aids used by teachers in class

3. Teachers' response to difficult grammar questions

4. Students' response to grammar questions and their performance in the grammar classroom

5. How textbooks and supplementary books were used in class.

After this step, the researcher met with the teachers and students from the 4 JHS schools at Nkwantanang cluster of schools participating in the study and briefed each group on the intended observation exercise. They all agreed to work with the researcher. She spent 4 weeks in the JHS classrooms to observe and gather information on the areas mentioned.

\section{Data Analysis and Discussion on Quantitative Study- STUDY 1}

Data analysis was based on the class tests conducted. Analysis of variance was adopted to assess whether the observed differences saw in the class tests were statistically significant.

\subsection{Analysis of Variance (ANOVA)}

Analysis of variance (ANOVA) is a statistical technique for comparing several population means.
Table 1. Anova of scores of class tests.

\begin{tabular}{lllll}
\hline Exam Score & & & & \\
\hline & Sum of Squares & Df & Mean Square & F \\
\hline Between Groups & 20.9923 & 3 & 6.9974 & 5.0772 \\
Within Groups & 192.948 & 140 & 1.3782 & \\
Total & 213.94 & 143 & & \\
\hline
\end{tabular}

To test the hypothesis that students taught grammar inductively will perform better than those who will be taught grammar deductively, The researcher selected a total of 72 students and grouped them into two groups of 36 students in a group, namely experimental group (pre exp), and for control group. Pre- tests were administered to members of both groups before the intervention. The intervention involved both groups but with different method of teaching. Test scores for pre- test and post test of the control and experimental groups were obtained and an analysis of variance was run to ascertain that mean differences in scores were significant to support the claim or otherwise that inductive method of teaching is better than the deductive method of teaching. The description of the significance is seen table 1 . On this table, F of 5.0772 showed a rejection of null hypothesis, which means that the between group mean which is 20.9923 is significantly different from zero. This implies that the two groups had different means.

\subsection{Test of Hypotheses}

Null hypothesis: Examination scores of students taught with inductive method is the same as examination scores of students taught with deductive method.

Alternate hypothesis: There is difference in examination scores of students taught with inductive method and that of those taught with deductive method.

From table 1, it can be seen that the Frequency calculated (5.0772) is greater than the critical value () read from the statistical table. This means that we reject the null hypothesis and accept the alternate and conclude that there is difference in mean scores.

A post hoc test is therefore performed to compare differences in mean scores and see which ones are statistically significant. In statistics, significance means 'probably true not due to chances'. This test look for evidence that you can reject the null hypothesis and conclude that the research intervention used has an effect. (Cohen 1988). To have a proof to the use of the effectiveness of an intervention, multiple comparison is used to compare the means. Multiple comparison is a method used to investigate differences between pairs of population means or, more generally, between subsets of population means using sample data. Once an Analysis of Variance (ANOVA) test is completed, the researcher may still need to understand the subgroup differences among the differences in scores of experimental and control groups. The subgroup differences are called "pairwise" differences. ANOVA does not provide tests for pairwise differences. Hence, the researcher needs to test pairwise differences, follow-up tests called post hoc tests are required (Mc. Hugh2011). 
Table 2. Multiple Comparisons/Post hoc comparisons in Anova.

\begin{tabular}{lllllll}
\hline \multicolumn{2}{l}{ Exam Score Tukey HSD } & & & & & \\
\hline (I) Group Name & (J) Group Name & Mean Difference (I-J) & Std. Error & Sig. & 95\% Confidence Interval & Upper Bound \\
\hline \multirow{2}{*}{ Precon } & & & & & Lower Bound & \\
& Preexp & 0.7500 & 0.2767 & 0.0375 & 0.0305 & 1.4695 \\
& Postcon & 0.3044 & 0.2767 & 0.6900 & -0.4150 & 1.0239 \\
Preexp & Postexp & -0.2794 & 0.2767 & 0.7439 & -0.9989 & 0.4400 \\
& Precon & -0.7500 & 0.2767 & 0.0375 & -1.4695 & -0.0305 \\
& Postcon & -0.4456 & 0.2767 & 0.3762 & -1.1650 & 0.2739 \\
Postcon & Postexp & -1.0294 & 0.2767 & 0.0016 & -1.7489 & -0.3100 \\
& Precon & -0.3044 & 0.2767 & 0.6900 & -1.0239 & 0.4150 \\
& Preexp & 0.4456 & 0.2767 & 0.3762 & -0.2739 & 1.1650 \\
Postexp & Postexp & -0.5839 & 0.2767 & 0.1549 & -1.3034 & 0.1356 \\
& Precon & 0.2794 & 0.2767 & 0.7439 & -0.4400 & 0.9989 \\
& Preexp & 1.0294 & 0.2767 & 0.0016 & 0.3100 & 1.7489 \\
\end{tabular}

*. The mean difference is significant at the 0.05 level.

\subsection{Multiple Comparisons/Post Hoc Comparisons in Anova}

From table 1, significant F- value indicated that there are differences in the means but the values did not indicate where exactly the differences were. To ascertain where the differences are, a post hoc/ multiple comparisons was adopted.

The table 2 had 6 columns with the following headings:

Mean difference: It gives the differences in means of control and the experimental pre- test and post- test.

Standard error: Is the difference between two means of the control and experimental group scores.

Sig-significance: The sig level indicates whether the variable is or is not significant. One needs to be 95 percent sure of the significance of $(\mathrm{p}<.05)$, this proves that figures given are not by chance but real.

Confidence level: It states how accurate the estimate of mean is likely to show. From current research, the multiple comparisons between the two groups are shown in Table 2 . From this table, it is obvious that the differences in mean between Pre con and Pre exp and difference between Pre exp and Post con are statistically significant at 0.05 level.

To explain further, the table 2 indicates that there are differences in the mean score for the pre experimental and post experimental which is -1.0294 and the significance value of 0.0016 . This means that the mean score for post-exp (inductive) is higher than post-control (deductive). From the significance found, the researcher can conclude based on the findings that inductive method of teaching of grammar impacted positively on the test scores of the students.

\section{Analysis and Discussion of Qualitative Data (Report on Observation) - STUDY 2}

\subsection{First Class Observation}

The topic the teacher treated was Nouns (common and proper nouns). Her objective was, at end of the lesson, students would be able to use common and proper nouns effectively in their essays.

The teacher wrote nouns on the chalkboard and asked students to pronounce the topic several times. After that, she asked the students for definitions of the topic. The teacher went ahead to explain the rules of common and proper nouns. Later, she asked the students to give examples and all examples given were written on the board for discussion. The teacher at this point explained the structures herself but did not allow the students to fish out for information themselves. After all explanations had been given, she asked the class whether the explanations were clear. As usual they all responded "Yes madam," but some were giggling and laughing. Concerning this particular lesson, the teacher did a lot of talking but there was less work for the students to do. The researcher observed that students really understood the lesson. All answers given were correct but because the students did not have enough practice, students are likely to forget what they have learnt. 68

\subsection{Second Class Observation}

The lesson notes structure was the same as the first school observed. There were no TLM to aid learning. The first thing was to write the topic "Perfect tenses"e on the board, then he asked students to give a definition of the topic given. The next thing he did was to review previous knowledge by taking the students through regular and irregular nouns and verbs. Students gave more examples for regular and irregular nouns. The teacher explained to the class the rule of perfect tenses that is, they are formed by the use of has/ have + past participle. Students now looked at the rules and formed their sentences. After all these exercises, students were given exercises in isolation, that is, sentences were given and they were asked to choose has/have and the right participle to that match. This exercise was an oral work. The findings were that teacher knew about his subject matter but how to impact to the students was a problem. Another issue was that the teacher was in haste to finish within the stipulated time. Finally, the teacher depended on the good students for answers to all questions asked. The weaker ones were in class alright but they were not concentrating. The teacher had 
to say keep quiet several times before they were quiet.

\subsection{Third Observation}

The teacher wrote her topic, "Conditional sentences" on the chalkboard and asked for the definition. The students were not giving right answers so the teacher asked them to open their textbooks and read definition from the books. With this exercise, the researcher observed that a lot of students did not take part because the textbooks were not enough. The teacher copied the definition 69 from the textbook on the board. From there, examples were given by the teacher and students were asked to read all examples in the textbook. The teacher selected good readers to read. Finally, students were asked to do exercises in the textbook into their grammar exercise books. The researcher's findings on observation were:

a) Grammar lesson was treated like a comprehension lesson.

b) Students were not given the chance to use the new structure.

c) The teacher talked was too much and made the lesson boring.

\subsection{Fourth Observation}

Topic treated was subject-verb agreement. The teacher wrote the topic on the board and asked students to repeat after her. She then gave an explanation of subject-verb agreement. She wrote her own examples on the board and asked students to identify the subjects and the verbs. After this, she told them that a singular subject goes with a singular verb and a plural subject goes with a plural verb. Teacher invited students to write examples of subject verb agreement on the board. Later all students read the sentences. After the teacher had taken them through the discussion, she started a sentence and asked them to complete it in their grammar books Findings of this lesson were that:

a) The teacher did most of the talking.

b) Students' understanding was tested by answering grammar exercises in isolation.

c) Students did not have enough practice. The method of teaching used was deductive teaching approach. 70

\section{Summary of Findings and Discussion}

\subsection{Findings and Discussion on Study 1}

To support or reject the hypothesis that students introduced to the inductive teaching approach would perform better than those taken through the deductive method, four tests were conducted. Two tests were conducted for each group, that is, control and experimental groups. Scores from the tests were recorded and analysed by the use of Analysis of variance (ANOVA). All tests were graded over 10. The results of all test recorded showed differences in the pretest and the post tests, as shown in table 2. It is obvious that the differences in mean between Pre-control and Pre-experimental and difference between Pre experimental and Post - control are statistically significant at the 0.05 level, which means there was an impact.
To explain further, it indicates that there are differences in the mean score for the pre experimental and post experimental is $(-1.0294)$. This means that the mean score for post-exp (inductive) is higher than the post-control (deductive). The researcher therefore concludes that inductive method of teaching grammar impacted positively on the test scores of the students. This is indicative that the inductive method is a better approach to teaching grammar. From the findings of this study, when teachers teach grammar in a real life situation, students can acquire the language more naturally. From the findings it can be said that teachers' methods of teaching are very important in the language classroom. Further, apart from the method teachers use in class, other factors, like teacher's experience, teachers' qualification, programme teachers studied and how often teachers attend workshops all play a vital role in the teaching of grammar. These factors can never be ruled out. For the effective teaching of grammar in our basic schools, there is the need to consider all the above factors discussed and equip the teachers with the necessary resources and capacity to improve the teaching of grammar.

\subsection{Findings and Discussion on Study 2}

For an effective lesson delivery at the JHS level, teachers need well planned lesson notes, and teaching and learning materials (TLM). On this note, the researcher took a look at the lesson plan for each of the lessons taught. What she observed was that the lesson plan structure used by all teachers in the participating schools was different from what the colleges of education taught 'the teacher trainees. Also, it was clear that some of the teachers had 'grandfather' notes, (notes from their predecessors) and all they need is to copy the notes for supervision by their head teachers and circuit supervisors but not to use in class. Also, from all the lessons observed, there were no TLM to help the students understand the structure being taught. Researcher observed lesson in four different schools.

\section{Educational Importance of Inductive Teaching of Grammar}

The aim of this study as stated earlier was to find out the impact of inductive teaching and learning of grammar in the selected basic schools. The findings based on this research, indicated the effectiveness of the inductive teaching method. Hence, there is the need for teachers and policy makers to popularize the importance and promote the use of the inductive teaching in Ghanaian schools. Below are some of the importance of using the inductive teaching approach:

i. Inductive teaching is learner - centred and help promote effective learning.

ii. It helps learners fish out information themselves.

iii. tudents hardly forget grammar structures that they learn.

iv. It has the guarantee to motivate students to learn the structures they are introduced to. 
v. It helps students to learn from the known to the unknown and this really helps students to understand structures by blending the old and the new knowledge.

vi. The grammar structures are learnt in real life situations and this situational learning encourages students to use the language in a real life situation.

vii. It also encourages teachers to give correct input when the need arises.

viii. It helps teachers to avoid long definitions they make students memorise.

Based on the findings of the research, the researcher proposed the following recommendations to help improve the teaching of grammar in the basic schools.

\section{Recommendations}

It is obvious from the findings that there was a lot to be done in the schools with regards to teaching of grammar at the JHS level. In order to help solve the perceived problem, the following suggestions are recommended. The recommendations were put under four areas, recommendation for students, teachers of English language, Ministry of Education and textbook writers

\subsection{Recommendation for Students}

One important issue is that students should desist from teasing their colleagues anytime they make mistakes in class and out of class. The researcher recommends that students are encouraged to read a lot because this will also help them identify how grammar structures are used. Also, being with the students for almost 4 weeks, the researcher saw that students nicked-named with errors they made in school. Examples of names heard were 'mengo' for mango, ladies and 'gentlement' for ladies and gentlemen,' plaster' for pressure, data of birth" for date of birth. The researcher realised that some students were not comfortable with these names so anytime they were answering a question in class and the friends mention such names, they fumble in their responses. They try to avoid errors. This behaviour really retards progress so students should stop teasing their colleagues so that they can learn the English structure freely.

\subsection{Recommendation for English Teachers at the JHS Level}

The researcher recommends strongly the use of inductive teaching approach, which involves realia /real objects, flash cards, writing pads, authentic texts (listening to recorded texts or listening to dialogues, and role-play) to highlight grammatical structures. Teachers should encourage their students to retell the stories in movies they watch. These are powerful tools which enhance and develop interest in learning at the JHS level. To add to the above points, teachers should create conducive atmosphere which will motivate learners to learn grammar.

Teachers should be discouraged from reading grammar textbooks in class. Instead they should take pupils through a lot of activities to make grammar lessons interesting. Mistakes from students' essays should be discussed with them. This activity should help students solve their grammatical problems.

\subsection{Recommendation for the Ministry of Education}

The Ministry of Education should work hand in hand with the training colleges because the researcher observed that the procedures teachers used in their various schools, are different from what teacher- trainees are taught in college. Since colleges of education have a role to play in improving teaching and learning in our schools, inductive teaching awareness of grammar should be created to help the traineeteachers to come out with the requisite skills to teach grammar effectively.

\subsection{Recommendations for Writers}

Grammar lessons should be incorporated in composition lessons because setting grammar questions in isolation would not help students to use the structures learnt effectively. Also, textbook writers should involve enough activities in their textbook and stop defining every aspect of grammar.

In order for the student to have a variety of textbooks, it is recommended that libraries should be opened in all schools.

It is the researcher's fervent hope that students, teachers and the Ministry of Education would take these suggestions seriously in order to help improve performance of English at the basic school certificate level.

\section{Conclusion}

In the language classroom it is expected that students are to acquire knowledge and apply it without difficulty but in the case of grammar, knowledge acquired is not being applied effectively. The mistakes some students make in their oral language and written essays attest to this fact. There is the need to handle teaching and learning of grammar in such a way that students will be able to acquire the knowledge and use it effectively. For instance, when we teach a pupil how to weave a basket, we expect the child to produce baskets but not to give the principles governing how a basket is made. For the teaching of grammar too, what teachers expect is learners will be able to use the structures effectively. Students do not need principles governing the Language but they need to apply whichever structures they learn. To add to this, findings from the study indicated that students lack practice. Practising grammar structures learnt is very important and helps one to grasp the structure easily. The Chinese adage, "I hear and I forget, I see and I remember, I do and I understand" explains it all. If students need practice to grasp the grammatical structures then teachers have a great task in the language classroom. This aspect is very important and it shouldn't be taken for granted because students hear a lot about the structures, they seem to forget all the rules, so for the child to understand grammar rules teachers are expected to take all students through a lot of activities to help them get 
first- hand experience and this will help them perform very well in the use of the grammar structures. Teachers must also discourage attitudes like, teasing their learners when they make grammatical error. Again, teachers should try their best to minimize apprehensions learners have towards learning of grammar. Whenever there is teaching, there should be a change in behaviour so there should be a change after going through grammar lessons. The researcher thinks that when students are taken through activities like picture description, storytelling, enough writing of exercises, role plays and videos it will enable students acquire the grammatical knowledge they need to use in their day to day activities. The researcher agrees with the earlier researchers who are advocating for the use of inductive teaching. Even though it is difficult to use but it is very useful when the language, one is learning is not his or her mother tongue.

\section{References}

[1] Armah, K. O. O. (2004). An analytical commentary on some telling grammatical errors on some frequency modulation stations in Kumasi, Ghana. Journal of science and technology 24 (2).

[2] Agor, J. T. (2003) Investigating English Language concord problems in the writings of Teacher -Trainees. (Unpublished thesis) University of Ghana.

[3] Asamoah, J. K., \& Wiafe, H. (2003) Teaching English in basic schools. Winneba: Institute Educational Development and Extension.

[4] Corbett, J. (2003). English Language Teaching. Australia: Library of Congress.

[5] Crystal, D. (2000). Language death. Cambridge: Cambridge University Press.

[6] Dadzie, G., \& Bosiwah, L. (2015). Spelling Errors among Junior High School. Journal of Language, Linguistics and Literature Vol. 1, No. 3, 2015, pp. 46-54.

[7] Dawson, C.(2009). Introduction to research: A Practical Guide for Anyone Undertaking Research (4 $4^{\text {th }}$ ed.). United Kingdom: A Division of How To Books Ltd.

[8] Foppoli, J. (2011). Is grammar really important for a second language learner? Retrieved on May 7, 2012 from http://www.eslbase.com/articles/grammar.

[9] Freeman, D. (2001). Teaching Grammar. In M. Celce Murcia (ed.), Teaching English as a Second or Foreign Language ( $3^{\text {rd }}$ ed., 25166). Boston, MA: Thomson/ Heinle

[10] Gay, L. R., \& Airasian, P. (2000). Educational Research: Competencies for Analysis and Application ( $6^{\text {th }}$ ed). Upper Saddle River, NJ: Merrill Prentice

[11] Griffee, D. T. (2012). An Introduction to Second Language Research Methods Design and Data. USA: Tesl - EJ Publishers.

[12] Johnson, C. S. (2011). School Administration and the Importance of Utilizing Action Research. International Journal of Humanities and Social Science, 1 (4), 78-84.

[13] Jupp, V. (2006). The Dictionary of Social Research Methods. New Delhi: Sage Publication Inc.
[14] Nunan, D. (1991) Language Teaching Methodology: A Textbook for Teachers. London: Prentice Hall International LTD.

[15] Nunan, D. (1999) Second Language Teaching \& Learning. Boston: Heinle \& Heinle Publishers.

[16] Paltridge, B., \& Starfield, S. (2007). Thesis and Dissertation in second Language: Handbook for supervisors. New york: Routlege.

[17] Sackeyfio, N. A (1996). Let's teach English. Accra: Assemblies of God Literature centre.

[18] Savage, L. K, Bitterlin, G., \& Price, D. (2010). Grammar Matters Teaching Grammar in Adult ESL Programs. New York: Cambridge University Press.

[19] Foppoli, J. (2011). Is grammar really important for a second language learner? Retrieved on May 7, 2012 from http://www.eslbase.com/articles/grammar.

[20] Hancook, D. R., \& Algozzine, B. (2006). Doing Case study Research, A Practical Guide for Beginner Researchers. New York: Teachers College Press.

[21] Lewin, Kurt. "Action Research and Minority Problems." Journal of Social Issues 2 (1946): 34-46.

[22] Susman Gerald I.(1983) "Action Research: A Sociotechnical Systems Perspective," ed. G. Morgan London: Sage Publications.

[23] Hurley, J. (1996) The foundations of dual language instruction/Judith Lessow-Hurley. 2nd White Plains, N. Y: Longman Publishers.

[24] Bitterlin, G. \& Salvage A.(2010) Grammar Matters: Teaching Grammar in Adult ESL Programs. Cambridge: Cambridge University Press.

[25] Thornbury, S. (1999)How to Teach Grammar 5th Edition. Essex: Pearson Education.

[26] Winter, R. (1989). "Some Principles and Procedures for the Conduct of Action Research." In O. Zuber-Skerritt (Ed.). New Directions in Action Research, London, Falmer Press.

[27] Brighton, C. M., \& Moon, T. R. (2007). Action research step by step: A tool for educators to change their worlds. Gifted Child Today, 30 (2), 23-27.

[28] Thornbury, S. (2000). How to Teach Grammar. Harlow: Longman.

[29] Fraenkel, J. R., \& Hyun, H. H. (2012). How to Research and Evaluate Research in Education. New York,

[30] Fraenkel, J. R \& Wallen, N. E. (2000). How to Design and Evaluate Research in Education, New York, NY: Mc Grawhill Companies Inc. N. Y: McGraw-Hill Higher Education.

[31] http://www.eslbase.com/teaching/grammar-important-secondlanguage-learner 20/2/15

[32] http://www.ghanawaec.org/Exams/examiner_BECE.aspx $18 / 01 / 2015$.

[33] http://www.tandfonline.com/doi/pdf/10.1080/0965079930010 102.

[34] www.nationaltechcenter.org/index.php/products/at-research 18/77 18/06/15.

[35] LA- Nkwantanang Composite Budget. Retrieved from the World Wide Web: www mofep.gov.gh 13/ 03/2015. 